3 Chakrabarti M, Suresh PN, Namperumalsamy P. Bilateral macular infarction due to diaminodiphenyl sulfone (4,4' DDS) toxicity. Retina 1999; 19(1): 83-84.

4 Kenner DJ, Holt K, Agnello R, Chester GH. Permanent retinal damage following massive Dapsone overdose. $\mathrm{Br} \mathrm{J}$ Ophthalmol 1980; 64: 741-744.

5 Leonard JN, Tucker WF, Fry L, Marsh RJ, Ford S. Dapsone and the retina. Lancet 1982; 1(8269): 453.

K Chalioulias¹, E Mayer ${ }^{1}$, A Darvay² and R Antcliff ${ }^{1}$

${ }^{1}$ Ophthalmology Department,

Royal United Hospital, Bath, UK

${ }^{2}$ Kinghorn Dermatology Department,

Royal United Hospital, Bath, UK

Correspondence: $\mathrm{K}$ Chalioulias,

Birmingham and Midland Eye Centre,

Dudley Rd, Birmingham B18 7QH, UK

Tel.: + 44177393 71372;

Fax: + 441215076773 .

E-mail: k_chal@hotmail.com

Eye (2006) 20, 943-945. doi:10.1038/sj.eye.6702050;

published online 7 October 2005

\section{Sir, \\ Endogeneous endophthalmitis caused by Sporobolomyces salmonicolor}

Endogenous endophthalmitis is intraocular infection resulting from haematogenous spread from a remote source. We report a case of endophthalmitis caused by Sporobolomyces salmonicolor in a reasonably healthy woman. To the best of our knowledge, S. salmonicolor endophthalmitis has not been previously reported.

\section{Case report}

A 31-year-old lady presented with a 3-day history of decreased vision in the left eye. She had been treated 2 years previously for pelvic inflammatory disease. Her visual acuity was 6/4 in the right eye and 6/18 in the left. The right eye was normal. The left eye showed fibrinous exudates in anterior chamber, posterior synechiae, and vitritis. She was commenced on oral prednisolone and intensive topical steroids, and a cycloplegic. FBC, ACE levels, anti-Toxoplasma $\mathrm{Ab}$ titre, Lupus anticoagulant, ANCA, and X-rays of the chest and sacro-iliac spine were reported normal. With little improvement over 2 weeks, vitreous biopsy and intravitreal injection of amikacin $400 \mu \mathrm{g}$, vancomycin $1 \mathrm{mg}$, amphoterecin $5 \mu \mathrm{g}$, and dexamethasone $400 \mu \mathrm{g}$ was performed. Vitreous sample showed pink colored yeast-like organism, possibly Rhodoturela. She was started on Tab. fluconazole $200 \mathrm{mg}$ twice a day. Vitreous sample was sent to a tertiary microbiology department where the yeast was identified as S. salmonicolor. Sensitivity recommended the use of voriconazole $200 \mathrm{mg}$ twice a day which was continued for 2 months. Improvement was seen within a week. Six months from presentation, the vitreous cavity remains clear on no antifungals with a final visual acuity of $6 / 12$

\section{Comment}

Risk factors for endogenous fungal infections include bacterial sepsis, corticosteroid therapy, immunosuppression, intravenous drug abuse, malignancy, alcoholism, and haemodialysis.

Sporobolomyces, a yeast closely related to Rhodoturela, is commonly isolated from environmental sources, such as air, tree leaves, and orange peels. The natural habitats are humans, mammals, birds, the environment, and plants. Infections that have so far been reported due to Sporobolomyces are lymphadenitis, ${ }^{1}$ dermatitis, ${ }^{2}$ cerebral infection, and fungemia. ${ }^{3}$ Although Rhodotorularelated endophthalmitis has been reported, ${ }^{4,5,6,7}$ ophthalmic infection caused by Sporobolomyces has not been previously reported.

Our patient had no obvious predisposing risk factors except for previous pelvic inflammatory disease which may have been a source. The low level of suspicion led to the use of systemic steroids prior to the use of systemic antifungal therapy and this may have contributed to the slightly prolonged course. It is therefore important to maintain a high level of suspicion and attempt to identify any possible infective pathogen in cases with unusual presentation.

\section{References}

1 Plazas J, Portilla J, Boix V, Parez-Mateo M. Sporobolomyces salmonicolor lymphadenitis in AIDS patient. Pathogen or passenger? Aids 1994; 8: 387-388.

2 Bergman AG, Kauffman CA. Dermatitis due to Sporobolomyces infection. Arch Dermatol 1984; 120: 1059-1060.

3 Rantala A, Niihikoski J, Lehtonen OP. Yeast in blood culture: impact of early therapy. Scand J Infect Dis 1995; 21: 557-561.

4 Dorey MW, Brownstein S, Kertes PJ, Gilberg SM, Toye B. Rhodotorula glutinis endophthalmitis. Canad J Ophthalmol 2002; 37: 416-418.

5 Merkur AB, Hodge WG. Rhodotorula rubra endophthalmitis in an HIV positive patient. $\mathrm{Br} J$ Ophthalmol 2002; 86: 1444-1445.

6 Pinna A, Carta F, Zanetti S, Sanna S, Sechi LA. Endogenous Rhodotorula minuta and Candida albicans endophthalmitis in an injecting drug user. Br J Ophthalmol 2001; 85: 759.

7 Gregory JK, Haller JA. Chronic postoperative Rhodotorula endophthalmitis. Arch Ophthalmol 1992; 110: 1686-1687. 
V Sharma, J Shankar and V Kotamarthi

Department of Ophthalmology,

Wrexham Maelor Hospital,

Croesnewydd Road,

Wrexham, Wales LL13 7TD, UK

Correspondence: J Shankar,

Tel: + 441978 725105;

Fax: + 441978725379

E-mail: jai_shobitha@tesco.net

Eye (2006) 20, 945-946. doi:10.1038/sj.eye.6702051;

published online 12 August 2005

Sir,

Persistent unilateral myopia following blunt trauma

Myopia after blunt ocular trauma is usually transient, resolving within weeks of the injury, and may be caused by ciliochoroidal oedema and thickening of the crystalline lens. ${ }^{1}$ This condition is distinct from bilateral accommodative spasm occurring after closed head injury, which may involve one or more elements of the near synkinesis and has variable periods of recovery. ${ }^{2,3}$ Here, we report a case of unilateral traumatic myopia that had not resolved 3 months after blunt ocular injury.

\section{Case report}

A 28-year-old woman had been struck in the left eye by hard, baseball-sized ball and presented with ocular pain and reduced vision. Her unaided acuities were 20/20 OD and counting fingers $O S$, but the injured eye improved to $20 / 30$ with a $-6.50 \mathrm{sph} /-0.50 \mathrm{cyl} \times 90^{\circ}$. Cycloplegic retinoscopy and refraction revealed $20 / 30$ vision OS with a plano $/-0.50 \mathrm{cyl} \times 90^{\circ}$ correction. The pupils were equal and reactive to light and accommodation. The anterior segments were clinically normal. The intraocular pressures were $10 \mathrm{mmHg}$ OD and $12 \mathrm{mmHg}$ OS, and the fundi were normal. Axial length was $24.18 \mathrm{~mm}$ in the right eye and $24.05 \mathrm{~mm}$ in the left. The anterior chamber depth was 2.85 and $2.94 \mathrm{~mm}$ and lens thickness was 3.68 and $4.60 \mathrm{~mm}$ in the right and left eyes, respectively.

After 3 months, the refractive findings were unchanged, and she was prescribed cyclopentolate $1 \%$ daily.

\section{Discussion}

Closed head trauma may cause bilateral accommodative spasm in young adults, which may be permanent. ${ }^{2}$ In addition, blunt ocular injury may cause a bilateral pseudo-myopia, ${ }^{4}$ which may be secondary to ciliary oedema and spasm. ${ }^{1}$ In our patient, the increased lens thickness was probably due to the induced accommodation. Given that the anterior chamber depth was greater in the injured eye, it is unlikely that the induced myopia was caused by anterior displacement of the lens iris diaphragm. To our knowledge, this form of traumatic myopia has not been previously reported to last more than several weeks. In this case, the pseudo-myopia was still present 3 months after the injury. Symptoms were relieved by cycloplegics.

\section{References}

1 Ikeda N, Ikeda T, Nagata M, Mimura O. Pathogenesis of transient myopia after blunt eye trauma. Ophthalmology 2002; 109(3): 501-507.

2 Goldstein JH, Schneekloth BB. Spasm of the near reflex: a spectrum of anomalies. Surv Ophthalmol 1996; 40(4): 269-278.

3 Monteiro ML, Curi AL, Pereira A, Chamon W, Leite CC. Persistent accommodative spasm after severe head trauma. Br J Ophthalmol 2003; 87(2): 243-244.

4 Doganay S, Er H, Hepsen IF, Evereklioglu C. Bilateral myopia following blunt trauma to one eye. Eur J Ophthalmol 2001; 11(1): 83-85.

LM Abraham, RD Keembiyage, D Selva and R Casson

Department of Ophthalmology, Royal Adelaide

Hospital, Adelaide, South Australia, Australia

Correspondence: R Casson, Department of Ophthalmology, Royal Adelaide Hospital,

Adelaide, South Australia, Australia

Tel.: + 61 (8) 82225222;

Fax: + 61 (8) 82225221.

E-mails: robertcasson@bigpond.com;

raheyes@mail.rah.sa.gov.au

Eye (2006) 20, 946. doi:10.1038/sj.eye.6702055;

published online 26 August 2005

Sir,

Plexiform neurofibroma masquerading as a persistent chalazion - a case report

Neurofibromatosis Type 1 (NF1) is an autosomal dominant disorder that commonly presents with 